\title{
Behaviour of Ionic Liquid-Derived Naphthenate Salts Under Desalting Conditions
}

\author{
Azlan Shah Hussain ${ }^{1 *}$, Poh Gaik Law ${ }^{1}$, and Jamali Basar ${ }^{1}$ \\ ${ }^{1}$ PETRONAS Research Sdn. Bhd., Lot 3288 \& 3289, Off Jalan Ayer Itam, Kawasan Institusi Bangi, 43000 Kajang, Selangor Darul \\ Ehsan, MALAYSIA
}

\begin{abstract}
Pyrenees crude oil containing high napthenic acids (NAs) content of more than $1.6 \mathrm{mg}$ $\mathrm{KOH} / \mathrm{g}$ oil was treated with methyltrimethylammonium methylcarbonate $\left[\mathrm{N}_{4441}\right]\left[\mathrm{MeCO}_{3}\right]$ as to reduce its acidity to the refinery permissible limit of $0.3 \mathrm{mg} \mathrm{KOH} / \mathrm{g}$ oil. The treated crude oils are subjected to Emulsion Stability Test (EST) as to mimic the operating conditions of a desalter. The results indicate the electrostatic conditions can facilitate the recovery of the napthenate salts post neutralization with high recovery rate of more than $79.6 \%$ with basic sediments \& water (BSW) to be $1.96 \%$. The conductivity of the treated crude oil also was found to increase as a function of temperature. The ionic liquid mediateddeacidification of crude oil can be performed under existing desalting conditions should the recovery of the naphthenate salts is acceptable at $70 \%$.
\end{abstract}

\section{Introduction}

High acid crude oils (HACs) are defined as crude oils that have Total Acid Number (TAN) of more than $0.5 \mathrm{mg} \mathrm{KOH} \cdot \mathrm{g}^{-1}$ oil and can go up to $8.00 \mathrm{mg}$ $\mathrm{KOH} \cdot \mathrm{g}^{-1}$ oil [1-5]. Total Acid Number (TAN) refers to the content of organic or inorganic acids presents in the crude oil and commonly defined as the amount of potassium hydroxide $(\mathrm{KOH})$ in milligrams required to neutralize one gram of crude oil $[6,7]$. The most common method used is ASTM D664 which measures the potential difference of initial crude oil and neutralization point.

Naphthenic acids (NAs) are the main reason that gives high acid crude oils (HACs) its unique characteristic. Naphthenic acids are carboxylic acids with one or more carboxylic acid functionalities attached to one or more saturated cyclic structure, in general. They can also refer to other chemical structures containing carboxylic acids such as heteroatom ( $\mathrm{S}, \mathrm{N}, \mathrm{B})$ or aromatics derived structures [8-13]. The general accepted concept of naphthenic acids is it can be commonly written as $\mathrm{C}_{\mathrm{n}} \mathrm{H}_{2 \mathrm{n}+\mathrm{z}} \mathrm{O}_{2}$ with $\mathrm{z}$ values corresponds to the degree of hydrogen deficiency that starts from zero to negative even integer. Much of the acidity in HACs originated from the presence of, but not limited to, naphthenic acids. The origin of naphthenic acids is thought to come from two main sources: a) from the geological formation of the reservoir i.e. rocks and presence of sulphur containing compounds and b) the results of biodegradation of oil-originated or biologicaloriginated compounds by microorganism and their by-products thereof [14-17]. The latter point has evolved into an important indicator of the maturity and state of the degradation of the oil in the field.

Recent review provides an overview of techniques used to reduce or eliminate NAs in crude oils which include esterification, decarboxylation and neutralisation with metal hydroxides [18-19]. Ionic liquids or ionic liquidbased chemistry were explored as a method to reduce or eliminate NAs due to its tuneable properties i.e. solubility, low volatility and basicity [20-23]. Manan et. al. demonstrated the phase behaviour of cyclohexanoic acid, a model napthenic acid with different ionic liquids of which the solubility of cyclohexanoic acid is dependent on lipophilicity of the cation and coordinating capability of the anion such as triluoroacetate and triflate [24]. However, with increasing alkyl chain of the cation, so does the solubility of dodecane indicating higher loss of hydrocarbon. Similar observations were also made with phenolate based ionic liquids [25]. Coto et. al. recently disclosed 1ethyl-3-methylimidazolium ethyl sulfate ([EMIM] $\left[\mathrm{EtSO}_{4}\right]$ ) achieved 25\% TAN reduction post contact with model oil system [26]. Functionalisation of the 1-butylimidazolium tetrafluoroborate $\left([\mathrm{Bmim}]\left[\mathrm{BF}_{4}\right]\right)$ cation moiety was found to increase the interaction between 
naphthenic acid and substitutional groups such as carboxylic acid (-COOH) and methyl ester ($\left.\mathrm{COOCH}_{3}\right)$ through formation of hydrogen bond [27].

Anderson et. al. describes the usage of two different classes of ionic liquids i.e. amino acid based ionic liquids (AAILs) and carbonate based ionic liquids, coupled with its efficiency of removing or neutralising napthenic acids in crude oil matrix [28, 29]. The mechanism of extraction is different for both classes of ionic liquids. The former suggested the mean of extraction is through formation of napthenate complex for the case of AAILs. While the latter is naphthenate salts formation through decomposition of the alkylcarbonate anion. Hydroxide based ionic liquids were found to be effective with tetralkylammonium cation being more efficient than tetralakylphosponium cation and can be regenerated using ion-exchange method [30].

Desalting process may provide the technique needed to remove the ionic liquids or its byproducts i.e. napthenate salts post contact with crude oil to allow recovery and reutilization of the reagent. Traditionally, desalter, which is the equipment that perform desalting function in a refinery is designed to remove inorganic salts and dehydrate through water-oil contact and hasten phases separation through coalescence of water droplets in a vessel that has electrostatic field generated in it [31-32]. There are two types of desalters which are Alternating Current (AC) and Dual Polarity. The main difference is the type of electrostatic field use as the latter employs both AC and DC field to induce calescence of water droplets. Removal of water and salts are important as failure to do so shall cause corrosion, fouling and increase of pressure in preheat train and downstream units [33].

Vadaraj et. al. described a technique of utilising desalter as means to contact mixture of aqueous alkoxylated tertiary amine with crude oil containing naphthenic acids $[34,35]$. The naphthenic acids shall form quaternary amine salts of which partitioned in the aqueous phase. However, there was evidence of $4 \%$ oil loss to the aqueous phase and no information on alkoxylated amine salt cross solubility into the oil phase was offered. Anderson et. al. demonstrated that recovery of naphthenate salts can be achieved up to $70 \%$ using $30 \mathrm{wt} \%$ water cut in a desalter which helps hasten the separation process [36].

This paper shall describe the behaviour of naphthenate salts, as a product of neutralisation between ionic liquids and naphthenic acids, in crude oil and water matrix and to determine the degree of emulsion resolution by electrostatic methods, thru Emulsion Stability Test (EST). Two main criteria were examined which are naphthenate salts recovery as a function of water cut and conductivity of the oil post neutralisation. The former is to understand the limit of desalter operation in term of water handling and the latter is to understand the effectiveness of Dual Polarity technology in resolving naphthenate salts solubility in water.

\section{Materials and Methodologies}

Pyrenees crude oil was supplied by PETRONAS from Australia. Tributylamine (99\%), Deuterated benzene $\left(\mathrm{C}_{6} \mathrm{D}_{6}\right)$ and dimethyl sulfoxide (DMSO) were supplied by Sigma-Aldrich and dimethylcarbonate (99\%) was supplied by Alfa Aesar. Methanol (HPLC) grade was supplied by Sigma-Aldrich. Water used is purified water with conductivity of $18 \mathrm{mS} / \mathrm{cm}$. All chemicals are used as received unless stated otherwise.

\subsection{Synthesis of Methyltributylammonium methylcarbonate $\left[\mathrm{N}_{4441}\right]\left[\mathrm{MeCO}_{3}\right]$}

The preparation of methytributyllammonium methylcarbonate $\left[\mathrm{N}_{4441}\right]\left[\mathrm{MeCO}_{3}\right]$ was performed according to published method [29]. Typically, the ionic liquid obtained by reacting the corresponding trialkyl amine $(0.2 \mathrm{~mol})$ with dimethyl carbonate $(36.03 \mathrm{~g}, 0.4 \mathrm{~mol})$ in $50 \mathrm{~cm}^{3}$ of methanol in an autoclave at 6 bar and $393.15 \mathrm{~K}$ for $12 \mathrm{~h}$. After the reaction the excess methanol was removed under reduced pressure and was washed with $n$-hexane ( 3 $\mathrm{x} 100 \mathrm{~cm}^{3}$ ) to remove excess dimethyl carbonate affording a light-yellow liquid. The yield (calculated using NMR) was $78 \%$ for the $\left[\mathrm{N}_{4441}\right]^{+}$ based ionic liquid. The ionic liquid was then further dried under high vacuum $\left(1.0 \times 10^{-3} \mathrm{~Pa}\right)$ at $338.15 \mathrm{~K}$ for $24 \mathrm{~h}$. The resultant ionic liquid crystallised upon standing at room temperature.

\subsection{Batch reactions for the neutralisation of Pyrenees crude oil with [ $\left.\mathrm{N}_{4441}\right][\mathrm{MeCO} 3]$}

Typical experiment was conducted by using $500 \mathrm{~g}$ sample size in a custom made double lined glass vessel (1 L capacity) with an overhead mixer with propeller type stirrer blade. The vessel was also equipped with metal baffles to assist mixing. The temperature control was provided by an automated water bath (Davidson \& Hardy Ltd. UK, model GD120). Crude oil was charged and left to equilibrate at the desired temperature for $1 \mathrm{~h}$. A known mass of ionic liquid was then mixed with 
the crude oil and reacted for 30 mins at a mixing speed of $800 \mathrm{rpm}$. The neutralised crude oil is used as it is.

\subsection{Emulsion Stability Test (EST)}

The Emulsion Stability Tester (EST) is a device designed to determine and compare the treatability of oil field emulsions and it is proprietary to Cameron Inc. The $200 \mathrm{ml}$ test setup aims to mimic the conditions within the pilot plant desalter and thereby allow early identification of emulsion problems and quick screening of potential demulsifiers. It utilises Dual Polarity technology of which combined $\mathrm{AC}$ and $\mathrm{DC}$ current at $6.5 \mathrm{kV}$. Equipped with a plotter, it provides a graphic representation of electrical dehydration. In the EST, a sample of emulsion is exposed to an electrostatic field and the energy and time required to coalesce and separate its components are determined and can be displayed graphically.

The EST has two completely isolated test cells, allowing evaluation of two samples simultaneously. Both the voltage and current of each electrostatic field are available for plotting. Typical experiment involved pre-mixing and heating $200 \mathrm{ml}$ mixture volume of pre-determine ratio of crude oil to water (1:1 to $1: 10)$ in Waring blender and at $80{ }^{\circ} \mathrm{C}(180$ $\left.{ }^{\circ} \mathrm{F}\right)$. The blending time is $30 \mathrm{~s}$. The mixture is then transferred into a glass cell in an electrostatic generator at temperature of $65{ }^{\circ} \mathrm{C}$. The mixture is the exposed to the electrostatic field until the mixture separates into two distinct phases visually or until pre-determined experimental duration is reached.

Prior tests have shown that this blending method provides more extreme mixing than what is possible with a standard desalter mixing valve or static mixer. If emulsions are easily resolved in the EST, then the lower temperature and less intensive mixing encountered in the pilot plant should result in a clean separation of the oil and water phases.

\subsection{Conductivity Testing}

The meter used for the test was built by Cameron, Houston to measure conductivity of crude oils at process temperatures. The $500 \mathrm{ml}$ oil sample is contained into a stainless-steel chamber under a minimum of 3.5 barg (50 psi) nitrogen pressure. In the chamber, there is a temperature sensor and a custom-built conductivity probe. All results below are based on a probe cell constant of $k=2100$ calibrated using a handheld conductivity meter at room temperature. The handheld device is designed to measure liquids using the ASTM D2624 standard test method. Since raw oil contains many complex chemicals, no absolute conductivity value is guaranteed, but relative values can be assured.

\subsection{Pyrenees Crude Oil Properties}

The testing methods are listed in Table 1 below.

\subsection{Quantification of naphthenate salt in water phase}

Quantification of naphthenate salt is performed using ${ }^{1} \mathrm{H}$ Nuclear Magnetic Resonance (NMR) and water suppression technique, WATERGATE (WATER suppression by Gradient-Tailored Excitation) as described elsewhere [37, 38]. Deuterated benzene $\left(\mathrm{C}_{6} \mathrm{D}_{6}\right)$ sealed in capillary tube was used as signal lock and a known amount of dimethyl sulfoxide (DMSO) was spiked in the sample as internal standard.

The ionic liquid recovery is expressed in mol\% based on ${ }^{1} \mathrm{H}$ NMR spectroscopy using DMSO as an internal standard and the methylene protons adjacent to the ammonium centre $\left(\mathrm{N}-\mathrm{CH}_{3}\right)$ as the cation signal. The molar amount of the recovered ionic liquid, $\mathrm{n}_{2}$ is calculated by integrating the signal attributed to the cation in reference to the internal standard signal based on Eq. (1).

Recovery of napthenate, $n_{2}=\alpha \times n_{\text {std }} \times \frac{P_{1}}{P_{2}}$

Recovery percentage, $\%=\frac{n_{2}}{n_{1}} \times 100$

where $\alpha$ is the total mass of extracted material $/$ mass used for NMR analysis, $\mathrm{n}_{1}$ is the amount of IL used and the expression $\mathrm{P}_{1} / \mathrm{P}_{2}$ is the ratio of the amount of proton of the cation signal over the amount of proton in the internal standard and $n_{\text {std }}$ is the mole amount of the internal standard used. The percentage IL recovery is then calculated from equation 2. 


\section{Results and Discussion}

\subsection{Pyrenees Crude Oil Properties}

The crude oil was tested for typical properties related to the operation of a desalter such as relative density, conductivity, salt content and water content. Table 1 listed all the properties tested and found it to be consistent with its crude assay [39].

Table 1. Raw Pyrenees Crude Oil Properties

\begin{tabular}{|c|c|c|c|}
\hline Property & Method & Unit & Value \\
\hline API & ASTM D287 & $\mathrm{n} / \mathrm{a}$ & 20.3 \\
\hline \multirow[t]{4}{*}{ Viscosity } & ASTM D341 & $\mathrm{cP} 30^{\circ} \mathrm{C}$ & 68 \\
\hline & & $\mathrm{cP} 40^{\circ} \mathrm{C}$ & 41 \\
\hline & & $\mathrm{cP} 50^{\circ} \mathrm{C}$ & 26 \\
\hline & & $\mathrm{cP} 60^{\circ} \mathrm{C}$ & 7.0 \\
\hline Conductivity & Proprietary & $\begin{array}{l}\mathrm{nS} / \mathrm{m} \\
@ 150^{\circ} \mathrm{C}\end{array}$ & 150 \\
\hline $\begin{array}{l}\text { Total Acid } \\
\text { Number }\end{array}$ & ASTM D664 & $\begin{array}{l}\mathrm{mg} \\
\mathrm{KOH} / \mathrm{g}\end{array}$ & 1.63 \\
\hline $\mathrm{BSW}^{*}$ & ASTM D4007 & $\%$ & 0.2 \\
\hline
\end{tabular}

*Basic Sediments and Water

\subsection{Emulsion Stability Test}

Emulsion stability was not a problem for neat Pyrenees mixed with 10 vol.\% water, as the emulsion separated clean and easily within 5 minutes. The response is graphically represented in Figure 1 below. The separation took place within 3 minutes with threshold voltage value of $4.6 \mathrm{kV}$ which indicated by the intersection of the blue and red line. The blue line indicates the conductivity of the oil phase and the red line is the voltage reading [40].

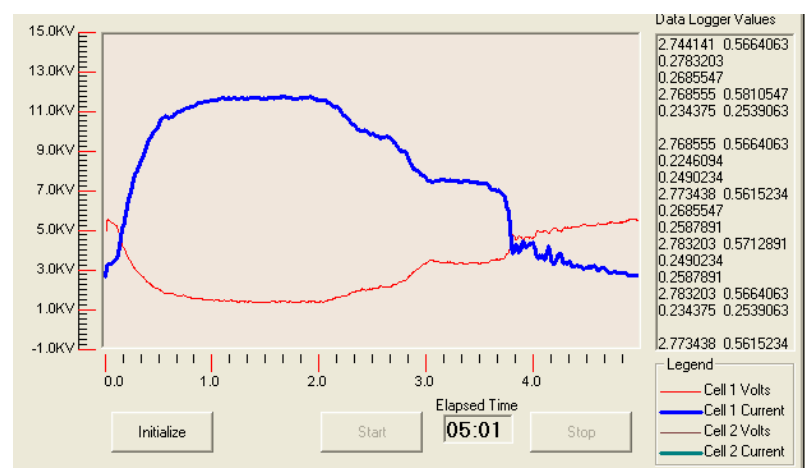

Fig. 1. Voltage and current (amps) as a function of time (minutes) for neat Pyrenees (no IL present) being separated from a 10 vol.\% water desalting
The desalter operation was mimicked by varying the volume of water from 10-40 vol.\%. All samples separated within five minutes except for the 10 vol.\% sample which showed a relatively poor separation even after 5 minutes EST duration. The rate of separation appeared to increase with higher $\%$ water volumes, with the $30 \mathrm{vol} . \%$ sample able to separate within $<30$ seconds. Table 2 shows the $\%$ IL-NA extracted as a function of water volume. 30 vol.\% water is thought to be the optimum volume of water needed to maximize the extraction of napthenate salts of average $79.6 \%$. The quantity of IL-NA extracted was measured by ${ }^{1} \mathrm{H}$ NMR analysis. An important factor to note is that there appears to be significant error in the test procedure. The 30 vol.\% water extraction was repeated three times and showed a variation of $14 \%$. The variation is thought to be contributed with heterogeneity of naphthenic acids itself as it formed the salt conjugate, therefore changing the solubility behaviour with water. The other factors would be attributed to mixing efficiency and presence of metal ions that could form tight hydrogen bond that leads to retention of water and naphthenate salts in oil phase [43].

The observation is consistent with Anderson et. al. with Doba crude oil of which the solubility of the naphthenates derivatives reached its maximum value in 40 vol.\% alcohol [29].

Table 2. Napthenate salts extraction as a function of water vol.\% from Pyrenees using the EST apparatus

\begin{tabular}{cccc}
\hline $\begin{array}{c}\text { Crude Oil } \\
\text { vol.\% }\end{array}$ & $\begin{array}{c}\text { Water } \\
\text { vol.\% }\end{array}$ & $\begin{array}{c}\text { \% IL } \\
\text { recovered }\end{array}$ & $\begin{array}{c}\text { BSW } \\
\text { vol.\% }\end{array}$ \\
\hline 60 & 40 & 0.73 & 2 \\
\hline 70 & 30 & 0.73 & 1.5 \\
\hline 80 & 20 & 0.77 & 2 \\
\hline 90 & 10 & 0.54 & 0.5 \\
\hline 70 & 30 & 0.86 & 2.6 \\
\hline 70 & 30 & 0.8 & 1.8 \\
\hline
\end{tabular}

A large amount of current flow was observed in all samples regardless of how much water had separated. This was not observed for desalting neat Pyrenees. This effect can be observed in Figure 2 below where the voltage remains low throughout the experiment, despite $>90 \%$ of the water phase having separated in $<2$ minutes. The explanation for this behaviour is presently unknown, but is likely to be related to unextracted IL-NA creating a conductive path between the two electrodes. The 
current across the cell remained high and never resolved.

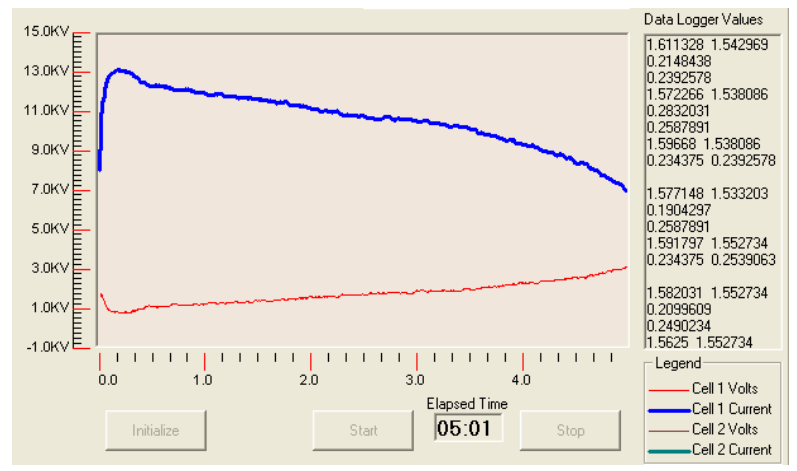

Fig. 2. Voltage and current (amps) as a function of time (minutes) for desalted Pyrenees neutralised with IL and being separated from a 30 vol.\% water emulsion

Increasing current across the electrodes will cause temperature increment of the process fluid as the time increases. Further experimentation was done to seek threhold voltage value via trial $\&$ error and the effect of starting voltage on the process fluid temperature. As more conductive the crude oil be, a lower voltage can be applied to lower down the current effect and obtain plurality of the phases. $2.5 \mathrm{kV}$ was found to be good at resolving the phases as shown in Figure 3 below. The phases were resolved with 1 minutes and at $2.5 \mathrm{kV}$ with 30 vol.\% water.

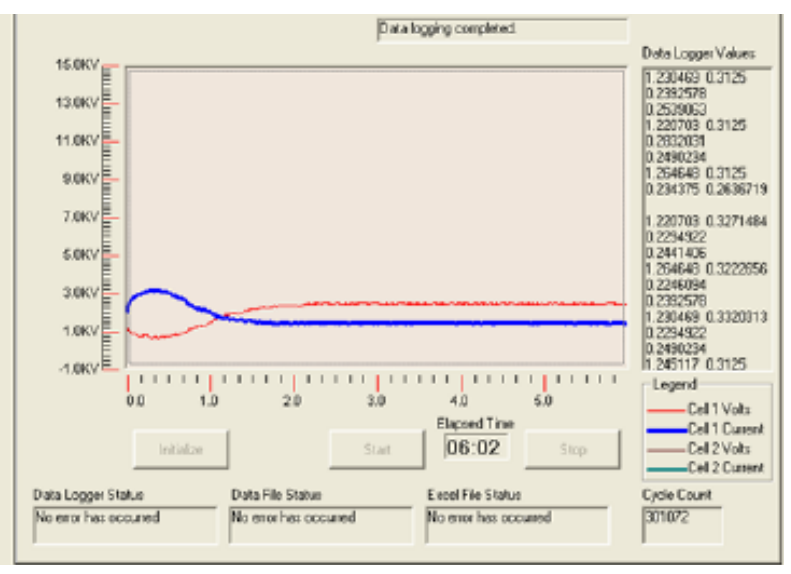

Fig. 3. Voltage and current (amps) as a function of time (minutes) at $2.5 \mathrm{kV}$ for desalted Pyrenees neutralised with IL and being separated from a 30 vol.\% water emulsion

The temperature effect was found to be evident. From Figure 4 below, the increase current across the electrodes causes seven (7) ${ }^{\circ} \mathrm{C}$ temperature difference after 5 minutes' exposure at $6.5 \mathrm{kV}$ initial voltage applied. In contrary, at $2.5 \mathrm{kV}$ threshold voltage, the temperature of the crude oil is more or less remain constant at $63{ }^{\circ} \mathrm{C}$. It can be argued that in $6.5 \mathrm{kV}$ case, the phase separation may have been affected by temperature instead of electrostatic field [41].

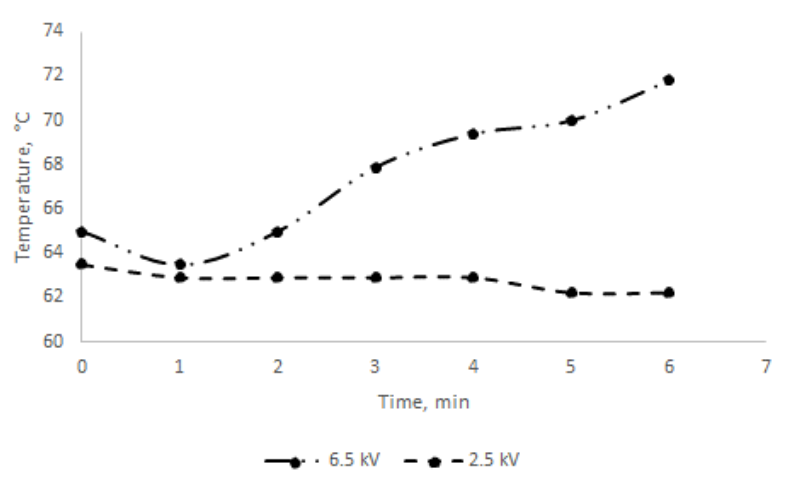

Fig. 4. The relationship between temperature and current exposure time in EST for initial threshold voltage of $6.5 \mathrm{kV}$ and $2.5 \mathrm{kV}$

\subsection{Conductivity Testing}

As per explained in the earlier sections, during EST test, it was observed that a large amount of current was flowing regardless of how much water had separated in the extraction of IL treated crude. And this was not observed for neat Pyrenees. Conductivity tests were performed to check the conductivity difference between neutralised (IL treated) Pyrenees crude and neat Pyrenees crude, and the result is shown in Table 3 and Figure 5 below. The neutralised crude oil is five (5) times more conductive than the neat crude oil, as shown in Table 3. Figure 5 confirmed the values reported in Table 3 by tracking the conductivity changes as a function of time. The observations were consistent as it was repeated of four (4) times. This will pose difficulty for the desalter to achieve its optimum voltage output and cause heavy load to equipment's transformer.

Table 3. Comparative conductivity values of neat Pyrenees crude oil and neutralised Pyrenees crude oil (napthenate salts were part of the oil matrix)

\section{Conductivity at Conductivity at} $25^{\circ} \mathrm{C} / \mathrm{nS} \mathrm{cm}^{-1} \quad 95^{\circ} \mathrm{C} / \mathrm{nS} \mathrm{cm}^{-1}$

\begin{tabular}{ccc}
\hline Neat Pyrenees & 5 & 102 \\
\hline $\begin{array}{c}\text { Neutralised } \\
\text { Pyrenees }\end{array}$ & 15 & 504
\end{tabular}




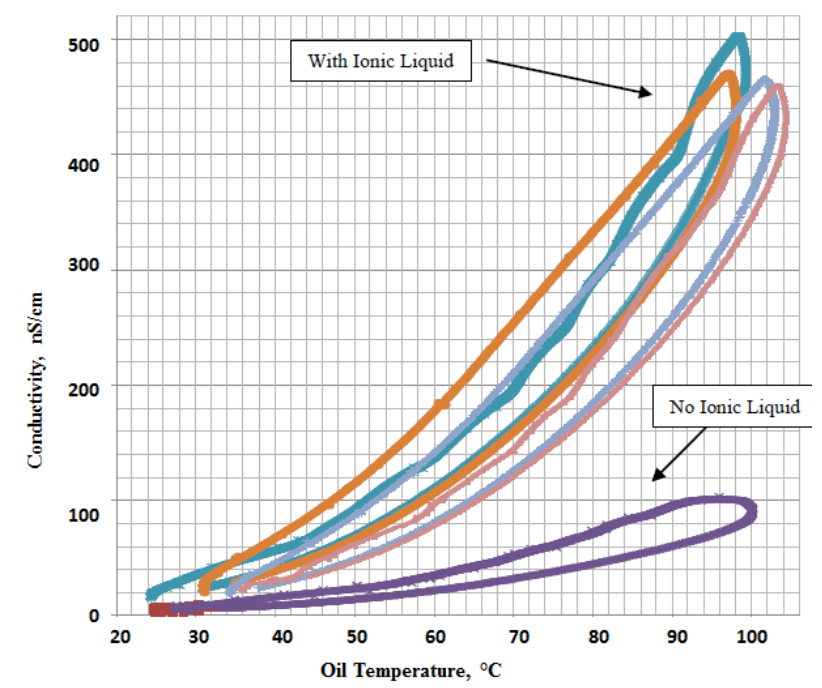

Fig. 5. Comparative conductivity of raw and neutralised Pyrenees oil (with different colours to denote different batches or repeats)

Further conductivity testing was made with Pyrenees crude oil that was neutralised and washed with water to see the conductivity source. From Figure 6, the maximum value of conductivity of the washed and neutralised oil was $55 \mathrm{nS} \cdot \mathrm{cm}^{-1}, 90 \%$ reduction of the value reported in Table 3 . Therefore, it can be concluded that the source of high conductivity is the presence of the napthenate salts in the crude oil. As the labile proton from the naphthenic acids was scavenged by the methyl carbonate anion to form carbon dioxide and water as suggested by Anderson et. al., the resultant napthenate anions of will become more lipophilic or hydrophilic based on its molecular weight [29]. In the previous work by Simon et. al. and Lutnaes et. al., there are also evidences of high molecular weight tetraprotic napthenic acid called ARN with molecular weight of $1230 \mathrm{~g} \cdot \mathrm{mol}^{-1}$, of which the resultant naphthenate salts would be lipophilic in nature [41, 42]. Similar range of napthenic acids could be present in this crude oil that would explain the remaining $20 \%$ non-recoverable napthenate salts.

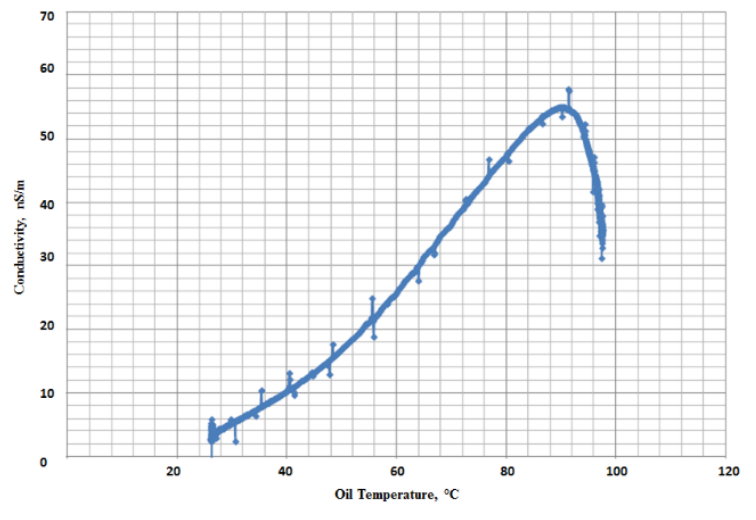

Fig. 6. Conductivity of washed and neutralised Pyrenees oil with relation to temperature

\section{Conclusion}

Two important parameters were examined in relation to using desalter as a technique for separation of napthenic salts from crude oil post treatment using ionic liquids which are extraction efficiency in the form of resolving phases and also conductivity of the crude oil. $79.6 \%$ recovery of naphthenate salts can be achieved with 30 vol.\% water cut under Dual Polarity (DP) technology with $2.5 \mathrm{kV}$ threshold voltage of under 2 mins. The short time required to resolve the phases would be translated into smaller vessel as it requires short residence time.

The oil in all cases exhibit high conductivity pre and post neutralisation. After washing with water, the oil has high conductivity of $55 \mathrm{nS} \cdot \mathrm{cm}^{-1}$ with slight higher BS\&W of $1.96 \%$ indicating tight emulsion of water droplet in crude oil. The results indicate that desalting technique can be used as means to separate naphthenate salts post neutralisation from crude oil and allows regeneration of the ionic liquids to be re-used in the system.

The work exemplified the use of a novel method which are facile and can be readily incorporated in the existing scheme of crude oil processing. Furthermore, the technique can be applied upstream as means to protect pipeline or even as means to upgrade the value of the crude oil itself as compared to other benchmark crude oils.

\section{References}

[1] J. Clemente, P. Fedorak, Chemosphere, 5, 585-600 (2005)

[2] G.C. Laredo, C.R. Lopez, R. Alvarez, J.J. Castillo, J.L. Cano, Energy Fuels, 6, 1687 (2004)

[3] S. Juan, S. Xian, Petrol. Sci. Technol. 14, 15341544 (2009) 
[4] W. Rudzinski, T. Aminabhavi, Energy Fuels, 2, 464-475 (2000)

[5] M. Mohammed, K. Sorbie, Colloids Surf. A., 349, 1-18 (2009)

[6] American Association for Testing and Materials International ASTM D 664: Standard Test Method for Acid Number of Petroleum Products by Potentiometric Titrations (2006)

[7] M. Barrow, J. Headley, K. Peru, P. Derrick, Energy Fuels, 5, 2592-2599 (2009)

[8] L.D. Brown, A.C. Ulrich, Chemosphere, 127, 276290, (2015)

[9] J. Clemente, P.A. Fedorak, Chemosphere,5, 585$600(2005)$

[10] T. Fan, Energy Fuels, 3, 371-375 (1991)

[11]K. Othmer, Kirk-Othmer Encyclopedia of Chemical Technology; John Wiley \& Sons: New Jersey (2007)

[12] K. Qian, W. Robbins, C. Hughey, H. Cooper, R. Rodgers, A. Marshall, Energy Fuels, 6, 15051511(2001)

[13] N. Tomczyk, R. Winans, J. Shinn, R. Robinson, Energy Fuels, 6, 1498-1504 (2001)

[14] A. Fafet, F. Kergall, M. Da Silva, F. Behar, Org. Geochem. 8, 1235-1242 (2008)

[15] W. Meredith, S. Kelland, D. Jones, Org. Geochem. 11, 1059-1073 (2000)

[16] J.S. Watson, D. Jones, E.P.J. Swannell, A.C.T van Duin, Org. Geochem. 10, 1153-1169 (2002)

[17] D. Gallup, J. Curiale, P. Smith, Energy Fuels, 3, 1741-1759 (2007)

[18] F.V. Adams, C.E. Chukwuneke, B.O. Agboola, Processing of Heavy Crude Oils: Challenges and Opportunities, IntechOpen, DOI: 10.5772/intechopen.89585 (2019)

[19] P.C. Mandal, M. Sasaki, Recent Insights in Petroleum Science \& Engineering, IntechOpen, DOI: $10.5772 / 65538$ (2018)

[20]P. Wasserscheid, T. Welton, Ionic Liquids in Synthesis; Wiley - VCH: Germany (2007)

[21] M. Deetlefs,K.R. Seddon, Chim. Oggi. 24, 16 (2006)

[22] T. Greaves, C. Drummond, Chem. Rev. 1, 206-237 (2008)

[23] H. Luo, H. Luo, J Phys. Chem. B, 13, 4181 (2009)
[24] N.A. Manan, M.P. Atkins, J. Jacquemin, C.H. Hardacre, D.W. Rooney, Sep Sci Tech. 47, 312324 (2012)

[25] S.N. Shah, M.I.A Mutalib, M.F. Ismail, H. Suleman, K.C Lethesh, R.M. Pilus, J. Mol Liquid, 219, 513-525 (2016)

[26] B. Coto, I. Suarez, M. Chirita, J. Conde, R. Gimenez, R.; Rodrigues, N. N. Alvarez, J.L. Pena, Sep. Purification Tech., 223, 15, 234-242 (2019)

[27] C. Wu, A. De Visscher, L.D. Gates, Sci Rep 176, doi:10.1038/s41598-017-18587-1 (2018)

[28] K. Anderson, P. Goodrich, C. Hardacre, A. Hussain, D.W. Rooney, D. Wassell, Fuel, 108, 2013, 715-722 (2013)

[29] K. Anderson, Atkins, M.P.; Goodrich, P.; C. Hardacre, A.S. Hussain, R. Pilus, D.W. Rooney, Fuel, 146, 60-68 (2015)

[30] S.N. Shah, M.I.A. Mutalib, R.M. Pilus, K.C. Lethesh, Energy Fuels, 29, 106-111 (2015)

[31] K, Zeidani, A. Bahadori, J. Canadian Pet. Tech, 44, 5 (2006)

[32] M. Goode, $5^{\text {th }}$ Intl. Conf. Refining Processes, AIChE, (2001)

[33] E.F. Pruneda, E.R.B. Escobedo, F.J.G. Vazques, J. Mex. Chem. Soc, 49 (1), 14-19 (2005)

[34] R. Varadaraj, D.W. Savage, W.E. Wales, US5961821A (1998)

[35] R Varadaraj, T.M. Pugel, D.W. Savage, US6096196A (2000)

[36] K. Anderson, A.S. Hussain, M. Atkins, J. Basar, WO2014016425A1 (2014)

[37] M. Piotto, V. Saudek, V. Sklenar, J. Biomol NMR, 2, 661-665 (1992)

[38] T.L. Hwang, A.J. Shaka, J. Magnetic Res. A., 112, 275-279 (1995)

[39] Pyrenees Crude Oil Overview, BHP (2009)

[40] J. Basar, K.A. Anderson, P.G Law, A.S. Hussain, Ionic Liquid Technology Deployment Project (ILTDP) - Crude Oil Deacidification (2013) unpublished

[41] S. Simon, E. Nordgård, O. Bruheim, J. Sjöblom, J.; J. Chrom. A, 1200, 136-143 (2008)

[42]B.F Lutnaes, J. Krane, B.E. Smith, S.J. Rowland, Org. Biomol. Chem. 5, 1873-1877 (2005)

[43]D.L. Gallup, J.A Curiale, Energy Fuels, 21, 17411751 (2007) 